\title{
Pengembangan ekonomi desa penghasil kopi melalui pemanfaatan ilmu pengetahuan dan teknologi di Kabupaten Belu
}

\section{Rachmini Saparita ${ }^{\star 1}$, Elok Wahju Hidajat ${ }^{2}$, \& Eki Karsani Apriliyadi ${ }^{1}$}

${ }^{1}$ Lembaga IImu Pengetahuan Indonesia

${ }^{2}$ Dinas Pemberdayaan Masyarakat Desa Kabupaten Belu

*rsaparita@gmail.com

\begin{abstract}
The activity aimed to develop coffee-producing villages economic in Belu Regency using science and technology in the community. Various parties (research and development institutions, central and regional governments, and villages) participated synergically in increasing institutional capacity of farmer groups and BUMDes, introducing science and technology utilization, guiding as well as providing production and marketing facilities, equipment for processing coffee commodities (upstream and downstream), providing facilities and infrastructure to access and support agricultural production. Those interventions are expected could transform coffee-producing village condition from lag behind to become developing villages.
\end{abstract}

Abstrak Kegiatan ini bertujuan mengembangkan ekonomi desa penghasil kopi di Kabupaten Belu melalui pemanfaatan iptek ke masyarakat. Berbagai pihak (lembaga litbang, pemerintah pusat dan daerah serta desa) bersinergi menjalankan program intervensi melalui peningkatan kapasitas kelembagaan kelompok tani dan BUMDes, pengenalan pemanfaatan iptek di masyarakat, pembinaan serta pemberian fasilitas produksi dan pemasaran, penyediaan peralatan pengolahan komoditas kopi (hulu dan hilir), penyediaan sarana dan prasarana untuk kemudahan akses dan penunjang produki pertanian. Intervensi tersebut diharapkan dapat mengubah kondisi desa penghasil kopi dari tertinggal menjadi desa berkembang atau maju.

Keywords: science and technology utilization; capacity building; coffee management; coffee processing; BUMDes

\section{OOPEN ACCESS}

Citation: Saparita, R., E. W. Hidajat, \& E. K. Apriliyadi. 2019. Pengembangan ekonomi desa penghasil kopi melalui pemanfaatan ilmu pengetahuan dan teknologi di Kabupaten Belu. Riau Journal of Empowerment 2(2): 81-91 https://doi.org/10.31258/raje.2.2.81-91

Paper type: Action research

Received: 2019-05-15 Revised: 2019-09-27 Accepted: 2019-09-29

Language: Bahasa Indonesia (id)

Funding: PPTTG LIPI dan Kementerian Riset Teknologi dan Pendidikan Tingg

ISSN 2623-1549 (online), 2654-4520 (print)

(C) 2019 Rachmini Saparita et al. The article by Author(s) is licensed under a Creative Commons Attribution 4.0 International License. This license permits unrestricted use, distribution, and reproduction in any medium, provided the original author and source are credited. 


\section{PENDAHULUAN}

Kabupaten Belu adalah salah satu kabupaten yang ditetapkan Pemerintah sebagai daerah tertinggal di Indonesia dilihat dari wilayah serta masyarakatnya yang kurang berkembang baik dari ketertinggalan ekonomi, sumber daya manusia (SDM), sarana dan prasarana, dan aksesibilitas, dibandingkan dengan daerah lain dalam skala nasional (Peraturan Pemerintah, 2015). Dari 76 desa, ada 68 desa di Kabupaten Belu yang ditetapkan sebagai desa prioritas sasaran pembangunan desa dan daerah tertinggal (Kementerian Desa, Pembangunan Daerah Tertinggal dan Transmigrasi, 2017). Kondisi tersebut cukup memprihatinkan, karena Kabupaten Belu mempunyai sumber daya pertanian yang cukup luas yaitu 53\% dari luas wilayah (sekitar 68 ribu ha) (Badan Pusat Statistik, 2017), yang dapat dimanfaatkan sebagai sumber penghasilan apabila dikelola dengan baik.

Jika mengacu pada kriteria Kementerian Desa, Pembangunan Daerah Tertinggal dan Transmigrasi (2017) tentang desa tertinggal, tujuh desa tertinggal di dua Kecamatan (Lamaknen Selatan dan Lamaknen) Kabupaten Belu adalah desa penghasil kopi. Pembangunan desa tertinggal harus dilakukan dengan berbagai strategi. Beberapa strategi pengembangan daerah tertinggal dikemukakan Syahza dan Suarman (2013), yaitu dengan memprioritaskan peningkatan ekonomi rakyat, peningkatan kualitas SDM, dan Pembangunan Infrastruktur. Sependapat dengan Syahza dan Suarman, Ramadhani (2018) juga mengusulkan bahwa strategi pembangunan yang harus diprioritaskan adalah pembangunan infrastruktur untuk mendukung pembangunan kawasan sentra komoditas unggulan (kopi) di Provinsi Lampung (Ramadhani, 2018). Dari hasil penelitian tersebut, maka desa-desa terpencil, khususnya desa penghasil kopi di Kabupaten Belu diarahkan seperti yang direkomendasikan Syahza dan Suarman (2013) dan Ramadhani (2018).

Untuk mendorong desa tertinggal menjadi desa berkembang dan maju, berbagai program pembangunan desa telah dijalankan dengan dana desa (Kementerian Desa, Pembangunan Daerah Tertinggal dan Transmigrasi, 2018b). Belajar dari kasus di Provinsi Papua Barat dan Papua, pembangunan desa dirasakan berjalan karena adanya dana desa (International Fund for Agriculture Development, 2018). IFRAD juga melaporkan bahwa dana desa di dua kabupaten tersebut sangat efektif dalam meningkatkan produksi pertanian. Belajar dari kondisi di Papua dan Papua Barat ini, maka penggunaan dana desa dapat dijadikan pemicu peningkatan pendapatan masyarakat di Kabupten Belu.

Komoditas kopi saat ini sudah menjadi primadona perekonomian beberapa desa di Pulau Jawa (Arifin \& Arianto, 2018; Sanaky \& Nashori, 2018; Rega, 2016), dan di Pulau Sumatera (Marlina, 2014; Ramadhani, 2018), juga di Pulau Ende, NTT (Rofi, 2018). Kemajuan desa penghasil kopi di Indonesia menjadi acuan juga pada kegiatan ini agar masyarakat desa penghasil kopi di Kabupaten Belu dapat merasakan kesejahteraan ekonomi karena mempunyai sumber daya perkebunan kopi yang baik.

Dari luas lahan pertanian yang ada, 20\% nya merupakan lahan perkebunan rakyat (Badan Pusat Statistik, 2017), yang salah satu komoditasnya adalah kopi. Meskipun tidak dominan, tetapi $61 \%$ perkebunan kopi (154 ha) terkonsentrasi di Kecamatan Lamaknen Selatan dan 11\% (27 ha) berada di Kecamatan Lamaknen (Badan Pusat Statistik, 2017). Sayang sekali produktivitasnya sangat rendah, hanya $279 \mathrm{~kg} / \mathrm{ha}$ (Badan Pusat Statistik, 2017), padahal produktivitas kopi nasional mencatat $720 \mathrm{~kg} / \mathrm{ha}$ (Badan Pusat Statistik, 2018). Dugaan produktivitas kopi di Kabupaten Belu yang sangat rendah ini karena pemanfaatan iptek pada komoditas kopi masih lemah. Benarkah demikian? Sejauh mana iptek telah dimanfaatkan masyarakat untuk pengelolaan dan pengolahan kopi di Kabupaten Belu saat ini? Apakah pengenalan dan pemanfaatan iptek dalam pengelolaan tanaman kopi dan pengolahannya dapat mendorong ekonomi desa berkembang? Program yang seperti apa yang dapat mendorong enonomi desa ke arah yang lebih baik? Itulah pertanyaan penelitan yang hasilnya akan dibahas pada tulisan ini.

Untuk menyelesaikan permasalahan pemanfaatan iptek yang rendah di masyarakat Kabupaten Belu, maka perlu adanya peningkatan penguasaan, pemanfaatan Iptek berbasis sumber daya alam setempat. Oleh karena itu kegiatan ini terlebih dahulu mengkaji kondisi 
pemanfaatan iptek pada pengelolaan dan pengolahan kopi di Kabupaten Belu saat ini melalui Focus Group Discussion (FGD). Identifikasi permasalahan iptek di masyarakat saat ini (real time) masih tetap diperlukan untuk menentukan tindakan aksi partisipasif seperti apa yang sesuai dengan kondisi masyarakat penghasil kopi yang akan diintervensi. Berbagai strategi diuraikan dalam menindak-lanjuti upaya pemanfaatan iptek pada petani kopi di Kabupaten Belu.

\section{METODE}

Salah satu tujuan kegiatan dengan tindakan aksi partisipatif (Participatory Action ResearchPAR) adalah untuk melihat realitas kehidupan di masyarakat secara lebih dekat, dan menyelesaikan persoalan yang dialami untuk mencapai harapan, yaitu transformasi (perubahan) ke arah yang lebih baik (Balakrishnan \& Claiborne, 2017). Menurut Balakrishnan and Claiborne (2017) PAR tetap konsisten dengan tujuan transformatif, tetapi juga tetap terbuka untuk mengidentifikasi persoalan lebih jauh lagi yang membahas masalah yang mendesak dalam masyarakat yang kompleks. Oleh karena itu PAR digunakan pada kegiatan ini, karena bertujuan melakukan perubahan ekonomi masyarakat desa melalui intervensi pemanfaatan iptek di masyarakat.

Pendekatan partisipatif yang berbasis masyarakat memang mensyaratkan bahwa anggota masyarakat dilibatkan dalam semua fase prosesnya (Makosky et al., 2010). Sementara Fletcher et al. (2015) menjelaskan PAR memiliki kekuatan dalam melibatkan dan mobilisasi pengetahuan (iptek) pada kondisi (waktu) yang sebenarnya (Fletcher et al., 2015). Dengan pertimbangan referensi-referensi tersebut, maka tindakan aksi partisipatif dilaksanakan di desa-desa penghasil kopi di Kabupaten Belu dengan melibatkan partisipasi masyarakat penghasil kopi.

Untuk mengidentifikasi kondisi pemanfaatan iptek di masyarakat saat ini, penggunaan FGD dipergunakan karena berbagai kelebihannya dalam memberikan kemudahan mendapat keterbukaan data dari peserta pada permasalahan yang dibahas secara efisien dan tepat waktu (Masadeh, 2012). Dan FGD telah menjadi metode popular saat ini (Bennett et al., 2017).

Untuk melihat pemanfaatan iptek pada komiditas kopi saat ini dan mengidentifikasi permasalahan pada produksi kopi yang produktivitasnya sangat rendah, maka data dikumpulkan melalui Focus Group Disscussion (FGD). Cara melakukan FGD mengikuti tahapan yang disampaikan Nyumba et al. (2018), dimulai dari: merancang disain riset yang terdiri dari penentuan tujuan, pemilihan partisipan, penentuan lokasi yang tepat; pengumpulan data, dimulai dari persiapan dan pelaksanaan FGD; Analisis isi data, dan perumusan hasil. Peserta FGD dipilih sebanyak 13 orang yang seluruhnya adalah petani kopi di wilayah Kecamatan Lamaknen Selatan dan Lamaknen, terdiri dari 10 laki-laki dan 3 perempuan. Umur peserta FGD berkisar antara 18-50 tahun.

Selain FGD, metode tindak aksi yang partisipasif dilaksanakan sebagai upaya mengintervensi pengetahuan masyarakat seperti yang digunakan Sunding dan Odenrick (2010), dalam bentuk pelatihan pengelolaan tanaman kopi dan pengolahan kopi pada petani/kelompok kopi. Untuk penguatan kelembagaan kelompok tani, dilakukan dengan penyuluhan dan pembinaan, serta pemberian (penggunaan) fasilitas desa.

Untuk memperdalam informasi, dilakukan wawancara pada beberapa tokoh masyarakat (Ketua Badan Usaha Milik Desa (BUMDes) Lakmaras dan Sekretraris Desa Lakmaras). Desa Lakmaras dipilih sebagai tempat FGD, pelatihan dan wawancara serta observasi di lapangan, karena paling mudah dijangkau oleh peserta dan peneliti, dan mempunyai hamparan tanaman kopi yang luas, sehingga bisa mewakili kondisi desa-desa lain penghasil kopi di Kabupaten Belu. 


\section{HASIL DAN KETERCAPAIAN SASARAN}

\section{Pemanfaatan Iptek dalam Pengelolaan dan Pengolahan Komoditas Kopi di Kabupaten Belu Saat Ini}

Dalam FGD terungkap bahwa petani kopi menemukan tanaman kopi secara turun termurun dan tidak pernah menanam. Selama ini masyarakat (petani kopi) membiarkan tanaman kopi tanpa perawatan. Masyarakat datang ke kebun kopi saat panen tiba. Dari observasi di lapangan terlihat tanaman kopi di Kecamatan Lamaknen Selatan tumbuh tidak berarturan jaraknya karena dibiarkan tumbuh sendiri (Gambar 1a, b). Hal ini bisa terjadi karena biji kopi yang jatuh ke tanah menjadi anakan kopi, dan dibiarkan tumbuh di tempat biji kopi tersebut tumbuh. Batang-batang tanaman kopi tidak beraturan, ada yang tumbuh sempurna, ada yang kurang sempurna (Gambar 1c, d).

Peserta FGD juga menyampaikan bahwa masyarakat tidak mengetahui cara memanen kopi yang baik. Seluruh kopi yang dipanen (dipetik) tidak dipilih, baik buah kopi yang berwana merah (matang), kuning (belum matang), maupun hijau (masih mentah) dipetik bersama (Gambar 1e). Buah kopi yang telah dipetik, lalu diperam beberapa hari bahkan bisa sampai minggu (cenderung menjadi busuk kulit buahnya), dibersihkan dari kulit buahnya (cherrynya), lalu dijemur di tanah (tanpa alas) sampai kering, menjadi kopi gabah. Hasil pengamatan di lapangan ditemukan tidak semua masyarakat menggunakan alas jemur kopi. Sebagian kecil menggunakan tikar (Gambar 1f). Hasil kopi gabah sangat beragam besarnya karena diduga berasal dari buah kopi yang dipetik tidak seragam kematangannya (Gambar 1f, g).

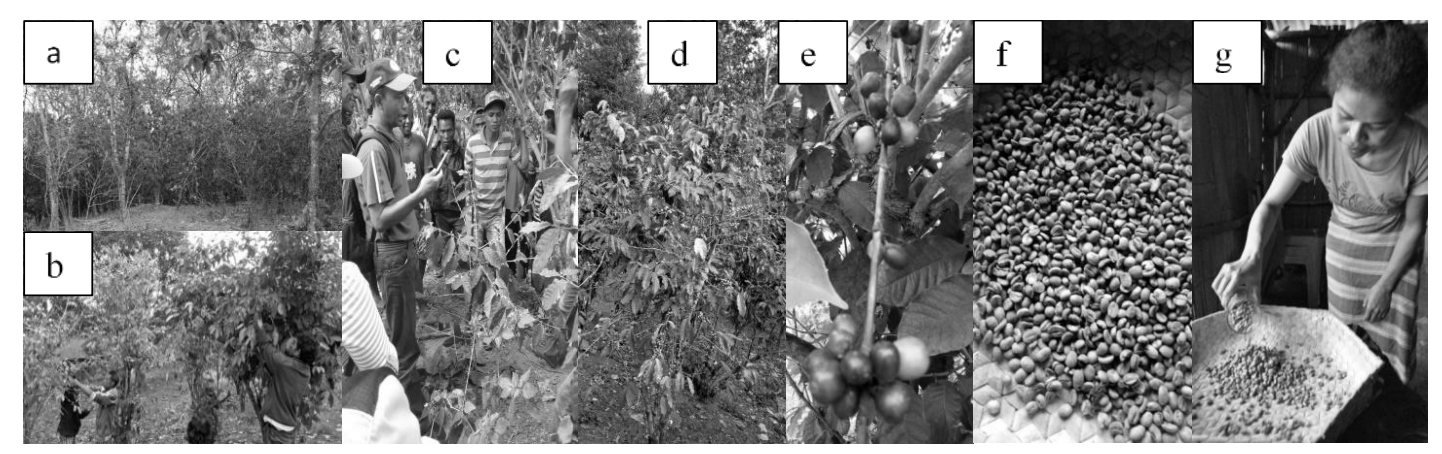

Gambar 1. Tanaman Kopi dan proses pengolahannya di Desa Lakmaras Kecamatan Lamaknen Selatan (a-g)

Dalam pengolahan kopi, peserta FGD menyampaikan bahwa masyarakat mengolah kopi menjadi kopi bubuk dengan sederhana. Kopi gabah yang telah kering (hasil dijemur di tanah) ditumbuk, menjadi kopi beras, lalu disangray di atas tembikar tanah. Setelah kopi matang, kopi sangray ditumbuk didan siap diminum untuk keluarga (tidak dijual).

Dari informasi yang terkumpul, baik dari FGD, pengamatan di lapangan ditambah dengan wawancara tokoh masyarakat, terlihat jelas bahwa masyarakat desa di Kabupaten Belu belum menggunakan iptek dalam mengelola tanaman kopi. Masyarakat belum mengetahui cara menanam, merawat dan hal lain terkait pengelolalan tanaman (kopi). Tanaman kopi yang ada hanya dikunjungi saat panen, lalu ditinggalkan, dan datang kembali ketika panen. Perilaku yang seperti itu bukan perilaku petani kopi, tetapi seperti perilaku nelayan untuk komoditas kopi. Perilaku tersebut sudah diwariskan secara turun temurun. Dalam mengolah kopi biji menjadi kopi gabah dan kopi beras, sampai kopi bubuk pun masih dengan proses yang sederhana dan konvensional, belum memanfaatkan teknologi yang telah berkembang saat ini. Masih rendahnya pemanfaatan iptek pada pengelolaan tanaman kopi di Kabupaten Belu merupakan salah satu penyebab produktivitas kopi di Kabupaten Belu rendah.

Rendahnya pemanfaatan iptek juga diduga karena kapasitas SDM yang rendah. Jika mengacu pada laporan Badan Pusat Statistik (2017), sebagian besar masyarakat berpendidikan rendah, yaitu $32 \%$ hanya lulus SD, 20\% tidak tamat SD, bahkan 9\% tidak bersekolah (Badan Pusat Statistik, 2017), sehingga kapasitas SDM di desa khususnya perlu ditingkatkan. 


\section{Mengangkat Desa Tertinggal menjadi Desa Berkembang dengan Iptek}

Berbagai upaya telah dilaksanakan oleh pemerintah pusat dan daerah dalam mendorong desadesa tertinggal di Indonesia, termasuk desa-desa penghasil kopi di Kabupaten Belu, antara lain dengan adanya dana desa yang cukup besar diberikan dan dikelola oleh desa di Indonesia. Namun upaya tersebut masih belum cukup. Diperlukan berbagai strategi dengan tindak aksi yang partisipatif untuk mendorong desa tertinggal menjadi desa berkembang melalui pemanfaatan iptek.

Berbagai tindak aksi partisipatif telah dilakukan kepada masyaraat desa penghasil kopi, seperti: (1) Penguatan kelembagaan kelompok tani dan BUMDes di Desa Lakmaras; (2) Peningkatan kapasitas iptek dalam pengelolaan dan pengolahan komoditas kopi; (3) Pemberian peralatan pengolahan kopi (hulu dan hilir); (4) Pendampingan berkelanjutan; (5) Pembangunan sarana prasarana jalan akses ke perdesaan; (6) dan sinergitas antar institusi dalam melaksanakan pembangunan desa, termasuk di desa-desa penghasil kopi di Kabupaten Belu ini.

\section{(1) Penguatan Kelembagaan kelompok tani dan BUMDes di Lakmaras}

Penguatan kelembagaan kelompok tani (kopi) dan BUMDes Lakmaras merupakan salah satu upaya dalam meningkatkan ekonomi desa penghasil kopi di Kabuaten Belu dari tertinggal menjadi berkembang (Hermanto \& Swastika, 2011), karena kelompok tani memiliki peran dan fungsi yang penting dalam menggerakkan pembangunan pertanian (Mosher, 1987). Belajar pada Hermanto dan Swastika (2011), penguatan kelembagaan dilakukan Lembaga Ilmu Pengetahuan Indonesia (LIPI) melalui penyuluhan akan pentingnya iptek di masyarakat dan bimbingan akan pentingnya struktur organisasi dan keberlangsungan kelompok tani kopi di tiga desa penghasil kopi (Desa Lakmaras, Desa Henes Kecamatan Lamaknen Selatan) dan Desa Duarasi (Kecamatan Lamaknen) untuk mulai berkerjasaman dengan BUMDes Lakmaras dalam penjualan kopi gabah.

Penguatan pada BUMDes dilakukan Pemerintah Desa dan Pemerintah Daerah melalui pemberian/penggunaan fasilitas produksi di Balai Desa (Lakmaras) selama BUMDes ini belum mempunyai rumah produksi sendiri. Akses permodalan usaha BUMDes diberikan melalui dana desa. Penguatan kapasitas kelembagaan BUMDes telah diperkuat oleh adanya kebijakan Pemerintah melalui pelaksanaan Peraturan Menteri Desa, Pembangunan Daerah Tertinggal, dan Transmigrasi Nomor 4 Tahun 2015 tentang Pendirian, Pengurusan dan Pengelolaan dan Pembubaran Badan Usaha Milik Desa.

\section{(2) Peningkatan Kapasitas Iptek Pengelolaan dan Pengolahan Komoditas Kopi}

LIPI sebagai Lembaga Riset telah lama melaksanakan program pemberdayaan masyarakat di masyarakat desa pnghasil kopi. Sejak 2003, berbagai pelatihan pemanfaatan teknologi tepat guna (TTG) pada pengolahan kopi 'hulu', dari pengolahan kopi buah menjadi kopi biji telah dilaksanakan di desa penghasil kopi (Lakmaras) Kabupaten Belu, sementara pelatihan pengolahan kopi hilir dan perbengkelan dilakukan kepada UMKM di Kota Atambua yang dekat ke konsumen (Dyah et al., 2006). Namun pada tahun 2007, peralatan TTG pengolahan kopi 'hulu' sudah tidak dapat difungsikan, karena alat telah usang dan rusak (Saparita et al., 2011). Sulitnya akses pada Desa Lakmarasa (saat itu), membuat desa penghasil kopi ini tetap terisolir, dan sulit mendapatkan bantuan perbengkelan (untuk perbaikan peralatan) yang berada di kota Atambua. Akhirnya masyarakat kembali menggunakan cara-cara manual dalam mengolah kopi buah menjadi kopi biji.

Pada tahun 2018 pelatihan pengelolaan tanaman kopi dilaksanakan pada kelompok tani di tiga desa penghasil kopi tersebut dilaksanakan oleh Puslit Koka dan LIPI. Materi pelatihan adalah tentang cara peremajaan tanaman, pemupukan, penanaman, pencegahan hama penyakit sampai cara okulasi tanaman kopi. Dengan pelatihan tersebut diharapkan masyarakat penghasil kopi mengerti dan menjalankan budidaya kopi yang baik, agar produksi kopi meningkat. 
Selain pelatihan pengelolaan tanaman kopi, Puslit Koka dan LIPI juga memberikan pelatihan pengolahan kopi (hulu dan hilir) pada kelompok tani di tiga dsa penghasil kopi dan BUMDes (Lakmaras). Selain di Desa Lakmaras, LIPI memberikan pelatihan pengolahan kopi hilir pada UMKM di Ibu Kota Kabupaten Belu (Kota Atambua), sebagai outlet pemasaran kopi di dalam dan keluar kota Atambua (melalui outlet di bandara A.A. Bere Tallo).

\section{(3) Pemberian Peralatan Pengolahan kopi (hulu dan hilir)}

Untuk peningkatkan pemanfaatan Iptek di masyarakat, Kementerian Desa, Pembangunan Daerah Tertinggal dan Transmigrasi (Kementerian Desa PDTT) memberikan bantuan peralatan pengolahan kopi yang lengkap (hulu dan hilir) beserta kendaraan pengangkut untuk penjualan kopi, kepada BUMDes Lakmaras di Kecamatan Lamaknen Selatan, Belu. Dukungan pemerintah desa adalah dengan pemberian fasilitas tempat produksi kopi bubuk bagi BUMDes, mendorong BUMDes Lakmaras dapat mengolah kopi gabah menjadi kopi beras dengan kualitas yang baik, sesuai standar kualitas yang ditetapkan pemerintah.

Peralatan pengolahan kopi hilir juga telah diberikan LIPI kepada UMKM di Kota Atambua sejak 2007, yang saat kegiatan ini dilaksanakan (2018) peralatan dan produksi (usaha) kopi bubuk masih berjalan.

\section{(4) Pendampingan yang berkelanjutan}

Peningkatan kapasitas iptek dilanjutkan dengan pendampingan kelompok tani, BUMDes dan UMKM oleh Pemerintah Daerah Kabupaten Belu (dari Bidang Pembangunan Kawasan Perdesaan, Dinas Pemberdayaan Masyarakat Desa (PMD)), bekerja sama dengan Bidang Perkebunan, Dinas Tanaman Pangan, Hortikultura dan Perkebunan. Himbauan untuk mencoba mengelola tanaman kopi semampunya (satu atau dua pohon kopi saja dulu) terus dilakukan oleh Pemerintah Daerah kepada pada masyarakat penghasil kopi, agar masyarakat dapat melihat perbedaan hasil (produktivitas) tanaman antara yang dirawat dengan yang tidak dirawat. Dukungan kebijakan dengan mempermudah perizinan usaha, penyaluran pemasaran dengan diberikannya outlet di Bandara A.A. Bere Tallo, terus dilakukan oleh Pemerintah Daerah. Pendampingan ini diharapkan terus menerus dijalankan. Peran pemerintah daerah dalam memajukan wilayah sudah terbukti penting (Dyah \& Saparita, 2009).

\section{(5) Perbaikan Sarana dan Prasaran untuk kemudahan akses antar desa dan kota}

Dalam 4 tahun pembangunan (2014-2018), Pemerintah Pusat melalui Kementerian PUPR telah membuat wajah baru kawasan perbatasan (termasuk Kabupaten Belu) menjadi embrio pusat pertumbuhan wilayah baru (Kementerian Pekerjaan Umum dan Perumahan Rakyat, 2018), melalui: pembangunan jalan Nasional; embung (Haekrit, Manleten, Fulur) sebagai cadangan air; sumur bor sebagai sumber air bersih (dekat jembatan Weutuh) untuk konektivitas antar desa, yang dapat membuka akses penghubung antar desa dan dapat mendorong ekonomi perdesaan.

Selain jalan nasional, jalan desa telah dibangun oleh Kementerian Desa PDTT (Kementerian Desa, Pembangunan Daerah Tertinggal dan Transmigrasi Republik Indonesia, 2018a). Dengan terbukanya akses dan koneksi antar wilayah di Kabupaten Belu diharapkan dapat memudahkan masyarakat untuk melakukan kegiatan perekonomian serta menjangkau ke pusat-pusat layanan sosial dan kesehatan, untuk bisa memasarkan hasil pertaniannya ke kota Atambua dan menghemat waktu, sehingga masyarakat desa bisa lebih meningkatkan produktivitasnya.

\section{(6) Sinergitas antar institusi dalam melaksanakan pembangunan desa}

Dalam mendorong desa tertinggal menjadi desa berkembang, saat ini pemerintah tidak bisa melakukannya secara parsial. Persoalan desa yang kompleks memerlukan penanganan berbagai pihak secara sinergi dan tidak tumpang tindih. Kasus desa-desa penghasil kopi di Kabupaen Belu melaksanakan kegiatan secara bersama dan bersinergi antar berbagai institusi 
pemerintah dan masyarakat, baik di tingkat pusat, daerah, bahkan sampai tingkat desa, seperti yang dianjurkan Saparita (2017). Sinergitas antar institusi untuk pengembangan wilayah desa tertinggal, telah dilakukan di desa-desa penghasil kopi di Kabupaten Belu, yaitu oleh LIPI, Puslit Koka, Kementerian Desa PDTT, Pemerintah Daerah Kabupaten Belu, Pemerintah Desa Lakmaras. Selain itu, Kementerian PUPR secara umum telah membangun sarana dan prasrana jalan (dan jembatan) dan penunjang produksi pertanian (bendungan, embung, sumur bor) bagi seluruh desa di Indonesia, termasuk desa-desa penghasil kopi di Kabupaten Belu.

Kegiatan sinergi antar institusi pemerintah dan swasta dalam berbagai program percepatan pembangunan daerah tertinggal harus terus dilaksanakan mengingat desa-desa tertinggal termasuk di Kabupaten Belu harus diberdayakan menuju Indonesia yang lebih baik.

\section{Harapan pada Desa-Desa Penghasil Kopi di Kabupaten Belu.}

Berbagai intervensi yang telah diberikan pada kelompok tani kopi oleh berbagai pihak memang belum memberikan dampak yang dapat diukur saat ini. Namun dari pengamatan di lapangan, adanya outlet di Bandara A.A. Bere Tallo Kota Atambua untuk penjualan usahausaha rumah tangga dan usaha kecil, khususnya usaha kopi bubuk, termasuk yang dihasilkan oleh BUMDes Lakmaras, UMKM kopi di Kota Atambua, memberi harapan akan adanya dorongan perubahan (transformasi) rantai pasok komoditas kopi. Mengacu pada hasil penelitian Rath dan Das (2016), bahwa manajemen rantai pasok dapat mengoptimalkan rantai nilai (ekonomi) perusahaan, maka pada kegiatan ini rantai pasok komoditas kopi di Kabupaten Belu digambarkan untuk menjadi dasar analisis transformasi ekonomi desa ke arah yang lebih baik.

Dari informasi yang terkumpul di FGD, saat ini masyarakat telah dibuat nyaman oleh adanya pembeli komoditas kopi (dan komoditas pertanian lainnya) sampai ke desa-desa di seluruh pelosok Kabupaten Belu. Kopi beras dibeli dari masyarakat dengan berbagai kualitas (tanpa di pilah) dan dari jenis kopi apapun, dengan harga Rp25.000/kg) dan dibayar tunai. Harga kopi sama saja, baik jika masyarakat menjual dalam jumlah sedikit maupun banyak, atau masyarakat menjual di desa maupun di Kota Atambua. Dari pengamatan di lapangan dan wawancara dengan tokoh masyarakat, pembeli kopi di Kabupaten Atambua itu ternyata Toko komoditas pertanian yang membeli (dan menjual) berbagai komoditas pertanian, berlokasi di Kota Atambua, yang mempunyai pegawai yang disebar ke pelosok desa di Kabupaten Belu. Berdasarkan informasi jumlah panen yang didapat, peserta FGD menyampaikan hampir seluruh kopi (sekitar 90\%) dijual melalui "pembeli" (pekerja toko) yang datang ke desa, sementara sebagian kecil (sekitar 5\%) langsung dijual ke Toko besarnya di kota. Sisanya, untuk minum keluarga (tidak dijual). Alur (rantai pasok) komoditas kopi di Kabupaten Belu tergambarkan seperti pada Gambar 2.

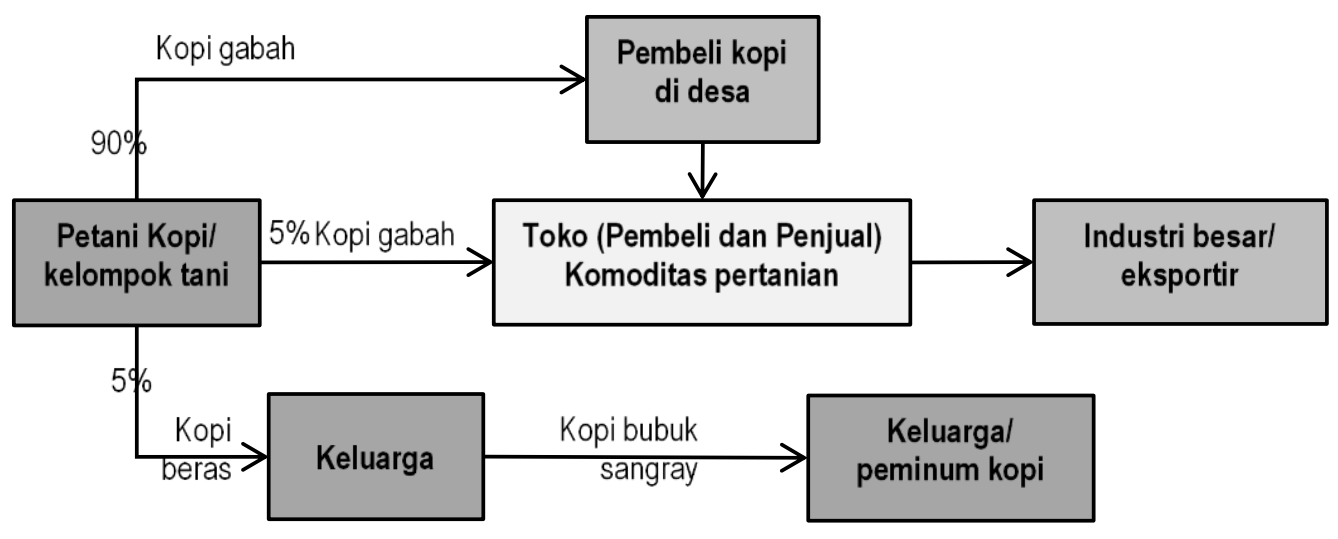

Gambar 2. Rantai pasok komoditas kopi di Kabuaten Belu yang terjadi saat ini

Rantai pasok komoditas kopi yang terjadi saat ini (Gambar 2), tidak mendorong petani dan kelompok tani kopi dalam menggunakan iptek. Harga kopi yang dijual tanpa ada pemilahan kualitas membuat petani kopi mengolah kopi sembarang saja. Proses berdasarkan iptek yang 
seharusnya dilaksanakan diduga akan memberatkan petani kopi jika nilai tambah pengolahan kopi tidak diterima petani. Nilai tambah dapat diterima melalui penerimaan harga yang lebih tinggi.

Harapan adanya tindakan aksi yang partisipatif pada kegiatan ini adalah adanya transformasi rantai pasok (Gambar 3) yang dapat berdampak pada ekonomi masyarakat desa penghasil kopi, dan menjadi jalan dalam mendorong peningkatan kondisi desa tertinggal menjadi menjadi desa berkembang, dan mandiri.

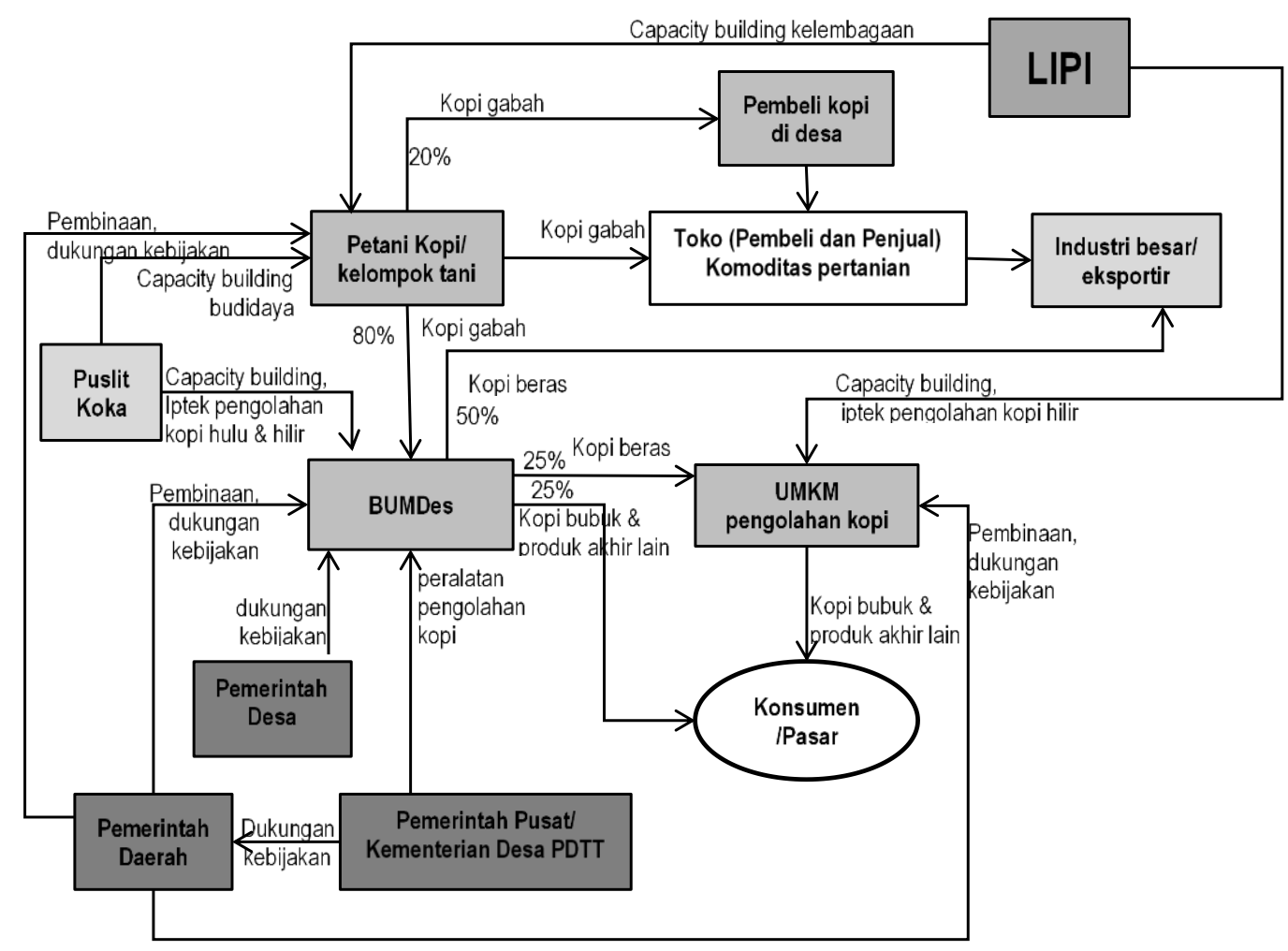

Gambar 3. Harapan Transformasi Rantai Pasok Komoditas Kopi karena peningkatan pemanfaatan Iptek di Kabupaten Belu NTT.

Perubahan rantai pasok komoditas kopi (dari Gambar 2 ke Gambar 3) tidak dapat langsung berjalan, karena harus terjadi perubahan perilaku beriptek, dari 'nelayan' kopi, menjadi 'petani' kopi, dari pengelolaan dan pengolahan kopi yang belum beriptek, menjadi pengelolaan dan pengolahan kopi yang beriptek.

Dari penelitian perubahan perilaku (dari belum ber-iptek menjadi ber-iptek), belum dapat dipastikan berapa lama perilaku berubah karena intervensi yang diberikan itu efektif dan manjur (Nielsen et al., 2018). Mempertimbangkan hal tersebut, maka pemerintah daerah sampai pemerintah desa yag setiap hari berada di wilayah desa dan masyarakat itu berada, harus terus berupaya membangun kesadaran pada pentingnya iptek untuk peningkatan pendapatan yang berdampak pada peningkatan kesejahteraan masyarakat dan desa itu sendiri.

Perubahan perilaku (dari belum beriptek menjadi beriptek) memang tidak bisa diharapkan dari intervensi pengetahuan dan informasi, bahkan Kelly dan Barker menjelaskan bahwa salah satu dari enam kesalahan adalah apabila menganggap perubahan perilaku karena adanya intervensi pengetahuan dan informasi (Kelly \& Barker, 2016). Oleh karena itu, program pembangunan peningkatan iptek di masyarakat harus dilakukan secara sinergi dengan berbagai pihak dan saling melengkapi bukan parsial dan tumpang tindih (Saparita, 2017).

Untuk mengubah rantai pasok komoditas kopi saat ini (Gambar 2) menjadi harapan (Gambar 3), perbaikian kualitas kopi harus dihargai dengan pembelian harga kopi yang jauh lebih baik dari yang terjadi saat ini (Rp25.000/kg kopi beras). Mengacu pada harga kopi standar yang dikeluarkan Direktorat Jenderal Perkebunan (2015), harga kopi beras yang 
diproduksi oleh petani Bali pada tahun 2015 bisa mencapai Rp46.000/kg, dan jika di ekspor bisa mendapatkan harga $\$ 3,526 / \mathrm{kg}$, maka masyarakat desa penghasil kopi di Kabupaten Belu diduga akan mendapat penghasilan yang lebih besar, sehingga kemungkinan besar bersemangan dapat menghasilkan dan menjaga kualitas kopi yang baik. Kondisi ini harus menjadi kebijakan pemerinah daerah terlebih dahulu agar masyarakat desa penghasil kopi mulai tergugah untuk berubah, dari masyarakat 'nelayan' kopi, mejadi 'petani' kopi.

\section{KESIMPULAN}

Pengembangan ekonomi desa penghasil kopi di Kabupaten Belu telah diupayakan berbagai pihak. LIPI dan Puslit Koka sebagai Lembaga Riset menjalankan tindak aksi melalui pengenalan pemanfaatan iptek di masyarakat dan peningkatan kapasitas kelembagaan desa, sementara Pemerintah Daerah Kabupaten Belu melalui pembinaan dan pembimbingan serta fasilitas produksi dan pemasaran. Pemerintah Pusat (Kementerian Desa PDTT) melakukan intervensi melalui penyediaan peralatan (teknologi) pengolahan komoditas kopi (hulu dan hilir), Kementerian PUPR melalui penyediaan sarana dan prasarana jalan, jembatan, embung, sumur bor untuk memudahkan akses dan penunjang produki pertanian. Sinergitas ini sangat diperlukan untuk menyelesaikan persoalan pembangunan desa agar dapat mendorong desa tertinggal menjadi desa berkembang atau maju. Berbagai intervensi yang telah dilaksanakan tersebut tidak akan berdampak jika tidak ada kemauan masyarakat pada transformasi kesejahteraan.

Untuk mewujudkan keberhasilan pemanfaatan iptek pada komoditas kopi di Kabupaten Belu, beberapa rekomendasi adalah:

1. Perlu pembinaan secara berkelanjutan untuk membangkitkan kesadaran dan kemauan masyarakat akan perubahan kehidupan yang lebih baik.

2. Perlu dibuat mekanisme yang jelas untuk membangun sinergi dan kerjasama dan jaringan kerja antara pemerintah daerah, pusat dan lembaga litbang (LIPI, Puslit Koka)

3. Perlu dilakukan evaluasi pada program yang berjalan secara bekesinambungan.

4. Perlu dukungan fasilitas peningkatan kapasitas kelembagaan kelompok tani kopi, kelembagaan BUMDes yang berkesinambungan.

5. Perlunya dukungan infrastruktur informasi dan transportasi umum ke desa penghasil kopi.

6. Perlu ada penyedian komoditas dalam jangka panjang, melalui pembukaan kawasan kopi. Jika melihat potensi tanaman kopi di Kabupaten Belu dan mengingat lahan tidur yang masih luas di Kecamatan Lamaknen Selatan dan Lakamnen, serta adanya program bantuan Dana Desa dari Pemerintah Pusat, maka Pemda Kabupaten Belu dapat mengarahkan pembangunan desa penghasil kopi menjadi kawasan desa kopi.

\section{UCAPAN TERIMA KASIH}

Tim peneliti mengucapkan terima kasih kepada PPTTG LIPI, Kementerian Riset Teknologi dan Pendidikan Tinggi atas pendanaan program ini. Terimakasih juga kepada pemerintah daerah dan berbagai pihak yang telah mendukung terlaksananya kegiatan ini.

\section{DAFTAR PUSTAKA}

1. Arifin, M., \& Arianto. 2018. Desa Penghasil Kopi Untuk Meningkatkan Ekonomi Masyarakat di Desa Damarwulan Kecamatan Keling Kabupaten Jepara. Abdimas: Jurnal Pengabdian

Masyarakat Universitas Merdeka Malang 3(1): 19-31.

http://jurnal.unmer.ac.id/index.php/jpkm/article/view/2247 
2. Badan Pusat Statistik. 2017. Kabupaten Belu dalam Angka 2017. Atambua: Badan Pusat Statistik Kabupaten Belu.

3. Badan Pusat Statistik. 2018. Statistik Kopi Indonesia 2017. Jakarta: Badan Pusat Statistik.

4. Balakrishnan, V., \& L. Claiborne. 2017. Participatory action research in culturally complex societies: opportunities and challenges. Educational Action Research 25(2): 185-202. https://doi.org/10.1080/09650792.2016.1206480

5. Bennett, N. J., et al. 2017. Conservation social science: Understanding and integrating human dimensions to improve conservation. Biological Conservation 205: 93-108. https://doi.org/10.1016/j.biocon.2016.10.006

6. Direktorat Jenderal Perkebunan. 2015. Statistik Perkebunan Indonesia 2015-2017 Kopi. Jakata: Kementerian Pertanian.

7. Dyah, S., \& R. Saparita. 2009. Peran Institusi Pemerintah Daerah Pada Pengembangan Inovasi Bagi Kesejahteraan Masyarakat. Bandung. 2009. Simposium Kebudayaan Indonesia-Malaysia (SKIM) XI. Bandung.

8. Dyah, S., et al. 2006. Pengembangan Wilayah Perbatasan Nusa Tenggara Timur Melalui Penerapan Teknologi. Subang: LIPIpress.

9. Fletcher, A. J., M. MacPhee, \& G. Dickson. 2015. Doing Participatory Action Research in a Multicase Study: A Methodological Example. International Journal of Qualitative Methods 14(5): 1-9. https://doi.org/10.1177/1609406915621405

10. Hermanto, \& D. K. S. Swastika. 2011. Penguatan Kelompok Tani: Langkah Awal Peningkatan Kesejahteraan Petani. Analisis Kebijakan Pertanian 9(4): 371-390.

11. International Fund for Agriculture Development. 2018. Village Development Programme (ex National Programme for Community Empowerment in Rural Areas Project). Asia and the Pacific Division Programme Management Department.

12. Kelly, M. P., \& M. Barker. 2016. Why is changing health-related behaviour so difficult?. Public Health 136: 109-116. https://doi.org/10.1016/j.puhe.2016.03.030

13. Kementerian Desa, Pembangunan Daerah Tertinggal dan Transmigrasi. 2017. Keputusan Menteri Desa, Pembangunan Daerah Tertinggal, dan Transmigrasi Republik Indonesia Nomor 126 Tahun 2017 Tentang penetapan Desa Prioritas sasaran pembangunan Desa, Pembangunan Daerah Tertinggal, dan Transmigrasi. Jakarta: Kementerian Desa, Pembangunan Daerah Tertinggal dan Transmigrasi.

14. Kementerian Desa, Pembangunan Daerah Tertinggal dan Transmigrasi. 2018a. Kemendes PDTT Bangun Jalan di Wilayah Perbatasan Republik Indonesia.

https://www.kemendesa.go.id/view/detil/2750/kemendes-pdtt-bangun-jalan-di-wilayahperbatasan-republik-indonesia. Diakses pada 2 Februari 2019.

15. Kementerian Desa, Pembangunan Daerah Tertinggal dan Transmigrasi. 2018b. Peraturan Menteri Desa, Pembangunan Daerah Tertinggal, dan Transmigrasi Republik Indonesia Nomor 16 Tahun 2018 Tentang Prioritas Penggunaan Dana Desa Tahun 2019. Kementerian Desa, Pembangunan Daerah Tertinggal dan Transmigrasi.

16. Kementerian Pekerjaan Umum dan Perumahan Rakyat. 2018. Laporan Kinerja Kementerian Pekerjaan Umum dan Perumahan Rakyat Tahun 2018. Jakarta: Kementerian Pekerjaan Umum dan Perumahan Rakyat.

17. Makosky, C. D., A. S. James, E. Urley, S. Joseph, A. Talawyma, W. S. Choi, K. A. Greiner, \& M. K. Coe. 2010. Using Focus Groups in Community-Based Participatory Research: Challenges and Resolutions. Qualitative Health Research 20(5): 697-706. https://doi.org/10.1177/1049732310361468

18. Marlina, L. 2014. Analisis Ekonomi Kopi Rakyat dan Peranannya Terhadap Perekonomian Wilayah Kabupaten Lampung Barat Provinsi Lampung. Thesis program magister, Institut Pertanian Bogor.

19. Masadeh, M. A. 2012. Focus Group: Reviews and Practices. International Journal of Applied Science and Technology 2(10): 63-68. http://www.ijastnet.com/journal/index/378 
20. Mosher, A. T. 1987. Menggerakkan dan Membangun Pertanian: Syarat-Syarat Pokok Pembangunan dan Modernisasi. Jakarta: CV Yasaguna.

21. Nielsen, L., M. Riddle, J. W. King, W. M. Aklin, W. Chen, D. Clark, P. Collier, C. Hunter, K. Kehl, R. King, L. Onken, J. M. Simmons, L. Stoeckel, C. Stoney, L. Tully, \& W. Weber. 2018. The NIH Science of Behavior Change Program: Transforming the science through a focus on mechanisms of change. Behaviour Research and Therapy 101: 3-11. https://doi.org/10.1016/j.brat.2017.07.002

22. Nyumba, T. O., K. Wilson, C. J. Derrick, \& N. Mukherjee. 2018. The use of focus group discussion methodology: Insights from two decades of application in conservation. Method in Ecology and Evolution 9: 20-32. https://doi.org/10.1111/2041-210X.12860

23. Peraturan Pemerintah. 2015. Peraturan Presiden Nomor 131 Tahun 2015. Tentang Penetapan Daerah Tertinggal Tahun 2009-2015.

24. Ramadhani, A. A. 2018. Strategi Pembangunan Daerah Tertinggal Di Kabupaten Lampung Barat. Universitas Lampung, Magister Ilmu Ekonomi, Fakultas Ekonomi dan Bisnis. Bandar Lampung: Universitas Lampung.

25. Rath, S. J. P., \& A. K. Das. 2016. Impact of Supply Chain Management Strategies on Changing Market Condition. IOSR Journal of Business and Management 18(1): 109-111. https://doi.org/10.9790/487X-1811109111

26. Rega, H. 2016. Analisis Rantai Pasok dan Kinerja Anggota Rantai Pasok Kopi Arabika di Kabupaten Garut. Disertasi Doktor, Institut Pertanian Bogor.

27. Rofi, A. 2018. Strategi Peningkatan Pendapatan Petani Kopi di Desa Boafeo Kecamatan Maukaro Kabupaten Ende NTT. Jurnal Geografi Indonesia 32(1): 77-83. https://doi.org/10.22146/mgi.33424

28. Sanaky, H. A. H., \& F. Nashori. 2018. Peningkatan Dan Pengembangan Produk Olahan Kopi Di Desa Brunosari. Asian Journal of Innovation and Entrepreneurship 3(03): 273-284. https://journal.uii.ac.id/ajie/article/view/11617

29. Saparita, R. 2017. Membangun Sistem Inovasi Pertanian Daerah Untuk Meningkatkan Pemanfaatan Teknologi di Masyarakat Tani. Jakarta: LIPIpress.

30. Saparita, R., et al. 2011. Pengembangan Masyarakat di Wilayah Perbatasan Nusa Tenggara Timur: Suatu Evaluasi. Jakarta: LIPI press.

31. Sunding, L., \& P. Odenrick. 2010. A Method for Action Research Interventions to Improve Joint Problem Solving in Operational Teams in the Swedish Construction Industry. Qualitative Research in Accounting \& Management 7(1): 97-123. https://doi.org/10.1108/11766091011034299

32. Syahza, A., \& Suarman. 2013. Strategi Pengembangan Daerah Tertinggal Dalam Upaya Percepatan Pembangunan Ekonomi Pedesaan. Jurnal Ekonomi Pembangunan: Kajian Masalah Ekonomi dan Pembangunan 14(1): 126-139. https://doi.org/10.23917/jep.v14i1.166 